\title{
A CASE OF PERINEO-SCROTAL DERMOID CYSTS.
}

\section{By ALBERT CARLESS, LONDON.}

THE nature and character of dermoid cysts are now so well known that unless there are special and peculiar features in a case, it is unnecessary to report them. In the present instance the condition is probably unique, and therefore worthy of publication.

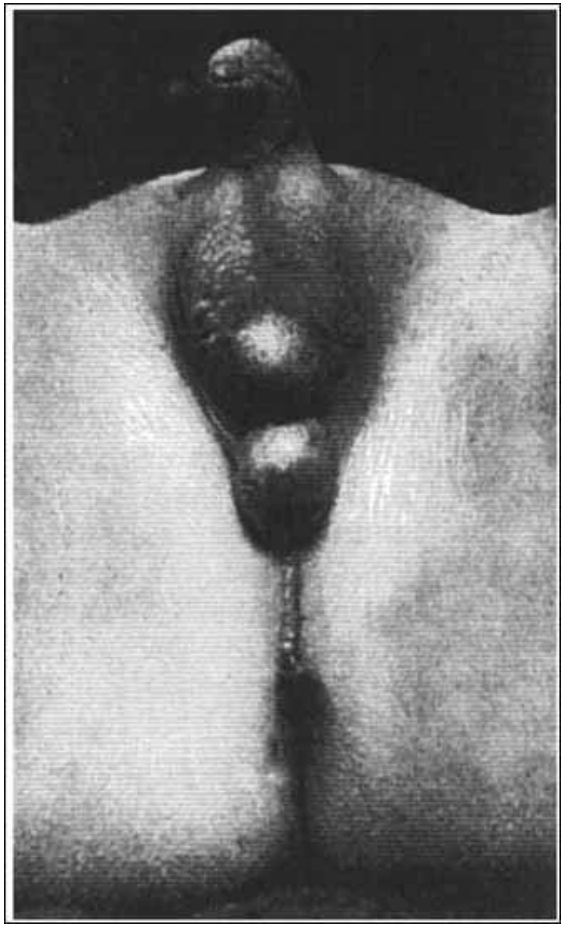

Fig. 8.-Perineal Dermoids, as they ordinarily appeared.

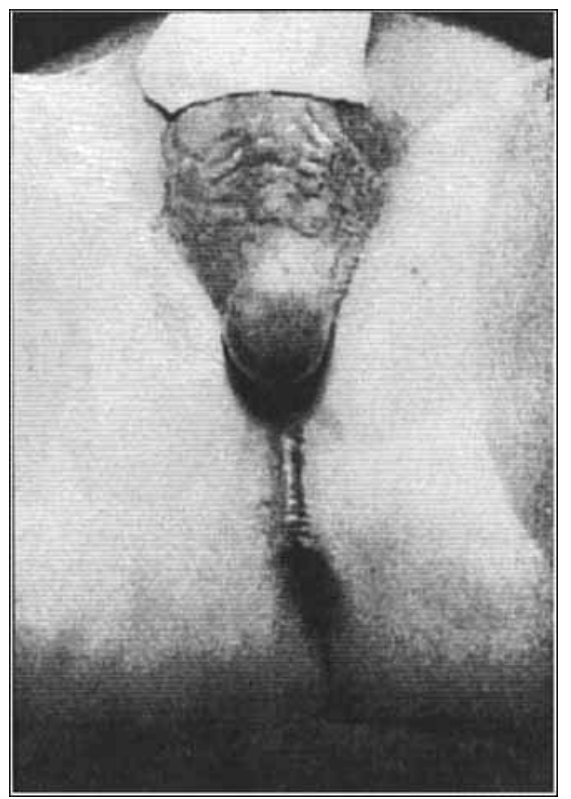

FiG. 9.-The anterior of the two cysts has been ermptied by pressure into the posterior, which is much distended, as is also the perineal tube extending back to the anus.

The patient, a boy aged twelve or thirteen years, was sent to me by Dr. Dupont, of Twickenham, complaining of two swellings in the perineum, which caused no pain or inconvenience except by their situation; the condition had been present since birth and was increasing slightly in size. On examination, two swellings about the size of marbles were found (Fig. 8), one situated in the posterior part of the scrotum, and the other at the anterior extremity of the perineum; they were separated from each other by an interval less than an inch in length, and were subcutaneous; there was no attachment to the deeper 
structures, and the skin, though tense, could be pinched up off them. There was an obvious communication between the two swellings, for one could be emptied into the other by pressure (Fig. 9) ; the sensation given to the fingers was that of thick fluid being expressed from one into the other cavity. The swellings were not translucent. Extending backwards from the posterior of the two swellings was a narrow median intradermic passage or track which reached as far as the anal margin ; this can be well seen in Fig. 8. It was obviously hollow, and could be emptied by running the finger from behind forwards, and then on pressure upon the posterior sac, a stream of the cyst contents could be seen rippling along the passage in the perineal raphe as far as the anal margin. Rectal examination demonstrated no abnormality. The testes were also normal, and had no communication with the swellings; the penis and urethra were normal and well formed. As the condition had existed since birth, and had only increased

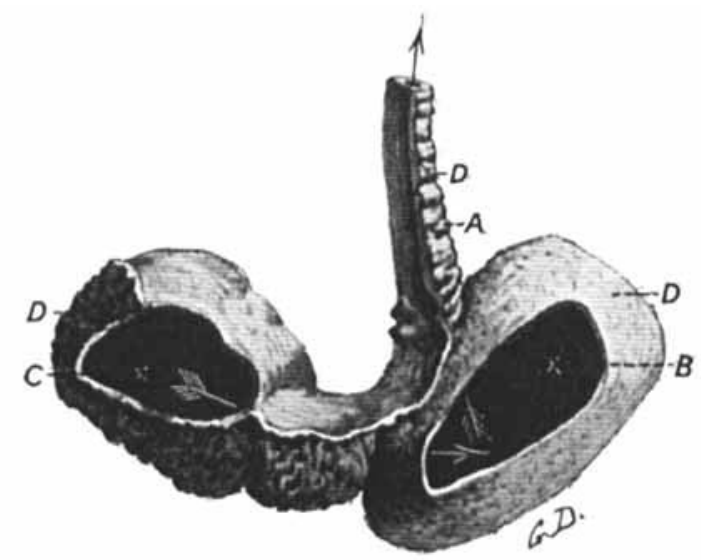

FIG. I0.-Specimen after removal. The posterior end of the perineal tube $A$ has been cut away for microscopic examination. $B$ and $C$ are the two communicating cysts. $D$ points to the skin. moderately in size, a diagnosis of perineal dermoids with extension backwards along the raphe was pronounced. The cysts and the narrow perineal canal were cleanly removed by dissection, and the case did perfectly well.

The specimen was handed over to the Museum of the Royal College of Surgeons, and the accompanying drawing (Fig. ro) has been made of the specimen after hardening in formalin, and it has therefore become somewhat distorted.

$A$ is the perineal tube, $30 \mathrm{~mm}$. long with a lumen $2 \mathrm{~mm}$. wide; it was filled with epithelial débris and lined by dermal epithelium; it lay in the perineal raphe, was quite superficial, and had a blind end posteriorly.

$B$. The posterior cyst was thin-walled, and measured 30 by $28 \mathrm{~mm}$.; it was distended with epithelial débris and lined by stratified epithelium flattened out by pressure.

$C$. The anterior cyst was about the same size, 30 by $25 \mathrm{~mm}$., and was covered by the scrotal dartos, so that the skin was somewhat rugose.

The interest of the case lies mainly in the existence of the perineal tube, which throws some light on other conditions. In this connection one cannot but refer to a case published recently by Dr. Edington, of Glasgow.1 In this instance a male child, two days old, came under observation for an imperforate condition of the anus, but the napkins were stained with meconium which escaped from an orifice at the back of the scrotum. The anal depression was shallow, and did not communicate with the bowel, but extending forward from it was "a nodulated ridge of some bulk" continuous with the perineal raphe. "The raphe from the anal depression forwards to the back of the scrotum was translucent 


\section{PERINEO-SCROTAL DERMOID CYSTS}

and of a blue colour, suggesting a tube containing meconium." Pressure from before backwards emptied the tube, which refilled from behind forwards on removing the pressure. In this case the raphe was excised. The communication with the bowel, which was very small, was laid open through the anal depression into the rectum, and the mucous membrane drawn down and sutured to the skin, with a good result. The canal in the raphe consisted of fibrous tissue lined with stratified epithelium.

Cases more or less similar in nature to Dr. Edington's have been frequently described, in which an imperforate condition of the anus has co-existed with an abnormal opening located in the female at the posterior end of the vulval orifice, and in the male at the back of the scrotum or on the under surface of the urethra. Openings into the bladder have also been known, but these latter are probably of a different nature and due to a partial persistence of the cloacal condition. In Dr. Edington's case, the abnormal passage was subcutaneous, and evidently not due to an abnormality of the cloaca.

My own case throws light on conditions such as this. It was obviously due to an error of development connected with the external genital folds. It will be remembered that about the second month of intra-uterine life, the genital eminence appears at the junction of the ventral surface with the posterior extremity of the body. From this is developed the penis in the male and the clitoris in the female. It is surrounded by an oval fold of skin, the genital fold which extends backwards on either side of the hind end of the spine, and thereby constitutes a shallow fossa at the bottom of which is the cloacal membrane. The posterior part of this fossa is separated from the anterior at a later date by the ingrowth on either side of a perineal fold. In the male, the groove or fossa in front of this disappears entirely, and the scrotum takes its place; in the female it remains as the vulva. The nonunion of the two segments in the male gives rise to the cleft scrotum occasionally seen in conjunction with hypospadias; a partial obliteration could perfectly well determine the conditions described above. In my own case the obliteration was complete except for a tiny track behind, and a larger bilocular cavity in front which constituted the dermoid cysts; in Dr. Edington's case a narrow passage persisted, extending back from the scrotum, and associated at that spot with an abnormal opening into the bowel.

\section{REFERENCE.}

1 Brit. Med. Jour. 1912, ii, 1373. 